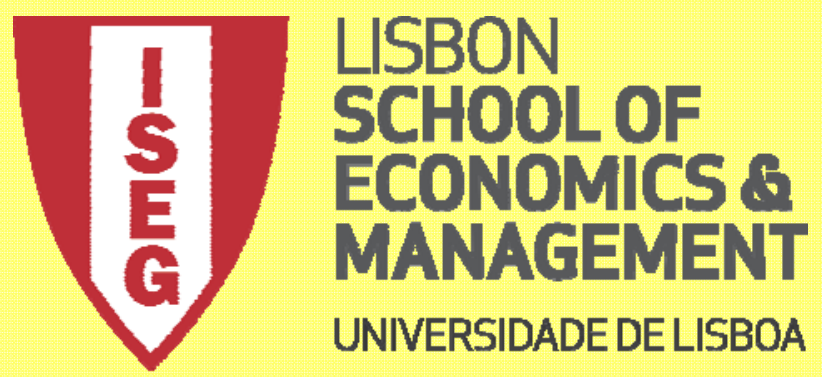

Department of Ec onomics

Isabel Mendes

Assessing the Values of Archaeological Heritage

WORKING PAPERS

ISSN 2183-1815

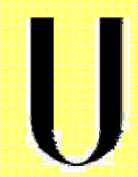

LISBOA 


\title{
Assessing the Values of Archaeological Heritage
}

\author{
Isabel Mendes ${ }^{(1)}$
}

(1) ISEG Lisbon School of Economics and Management, Department of Economics, SOCIUS-CSG Research in Social Sciences and Management, University of Lisbon. Rua Miguel Lupi, 20, 1249-078 Lisbon, Portugal; Author for

correspondence (midm@iseg.utl.pt).

\begin{abstract}
The main aim of this paper involves contributing to the discussion around the value of archaeological heritage through the lens of an economist. The path taken to achieve this main goal included three objectives. Firstly, there is the contribution towards clarifying the concept of archaeological heritage benefits by highlighting the complexity that stems directly from its holistic characteristic. Secondly, this also contributes to assessments of archaeological heritage economic and social benefits and values by demonstrating how they may be captured by means of a single variable measured in monetary units. Furthermore, and thirdly, this then helps explain how such a monetary variable may prove of use both to cultural heritage management for sustainable preservation and conservation improvement, and to the appraisal of the total private and public benefits arising out of preservation and conservation archaeologic heritage programs.
\end{abstract}

Key Words - Archaeological Heritage; Multi Values; Market and Non-Market Benefits; Valuation; Preference-Based Methods.

\section{JEL classifications: Z1, D11.}

\section{Introduction}

The first hypogeum necropolis discovered in the Alentejo [1], a southern Portuguese region, is composed of a vast set of graves with underground burial chambers with sections found well below the surface, excavated from the bedrock 4000 years Before Christ. Skeletons and various objects in stone and bone were also found on the site. The underground graves were previously unknown to archaeologists and the excavation works furthermore revealed how they coexisted with other megalithic funerary monuments relatively common in the region, such as dolmens. The archaeological discovery was emphatically classified as Very Important for the history of the region in so much as it completely changes the knowledge until recently held on the region's prehistorical burial practices. Such knowledge leads, for example, to the conclusion that the region displayed specific mortuary architecture and unique funerary rituals. The scientific importance and the specificity of such new knowledge have led researchers to recognize its high value potential. The valorisation process of discovery, however, raises some important questions. Is the necropolis a heritage cultural good sufficiently important to justify the allocation of scarce resources to preserve and conserve it? Do the host communities perceive the cultural importance of this discovery? Might these recently discovered archaeological remains serve to improve local economic and socially sustainable development? How valuable actually are they? In this paper, we put forward some responses to these questions. The hypogeum necropolis and its contents are what the Merrian-Webster dictionary defines as archaeological remains i.e. material traces of past human life and activities such as fossil relics, artifacts, and monuments (http://www.merriam-webster.com/dictionary/archaeology. Last accessed: 29th November 2015). International organizations (UNESCO, ICOMOS or ICCROM) classify archaeological remains as cultural heritage and, therefore, primary targets for preservation, conservation, 
and dissemination [2] (Recommendation concerning the protection of movable cultural property, adopted by UNESCO in Paris, November 28, 1978 (§ 1)) [3] and [4]. Informed elites such as academics, archaeologists, intellectuals or archaeological institutions, widely recognize the fundamental importance archaeological remains have for humanity as they constitute basic records about past human civilizations, cultures, and activities. Hence, these more informed social groups correspondingly tend to strongly defend the preservation of such remains while campaigning for the continuity of archaeological research and excavation activities. Nonetheless, there seems to persist a gap between the wants of such groups and the wants of others e.g. local populations that host these sites, local politicians and government, or private economic stakeholders. One main cause of this gap occurring stems from the well-known and common detachment non-expert stakeholders usually hold towards this type of heritage, which generally results from a lack of adequate cultural information. Cultural and archaeological organizations are well aware of this situation and to the point of broadly recognizing how the disclosure of archaeological knowledge to non-experts represents an essential function to promoting and improving information, communication and cultural linkages between the archaeological related agents and institutions, stakeholders, and populations. The act of communicating to hosts communities the significance of archaeological remains and the importance in preserving and conserving them therefore constitutes the primary objective of current heritage management policies [4, p. 4]. The importance of these communication based preservation strategies undoubtedly enforces the need to prove to non-experts how archaeological heritage is valuable both by clearly defining its potential economic and social benefits and by demonstrating which cultural and non-cultural activities - compatible with the primary preservation objective - may be implemented by stakeholders to capture the entire range of benefits. Bearing this in mind, cultural institutions identify activities such as domestic and international tourism as among the most important for disseminating and conserving cultural heritage with this, in turn, considered as "...the major tourism attraction" [3, p. 5]. The basic idea here incorporates guaranteeing all stakeholders gain full well managed physical, intellectual, and emotional contact with the archaeological heritage that will nurture "...a duty of respect for the heritage values, interests and equity of the present-day host community, indigenous custodians or owners of historic property and for the landscapes and cultures from which that heritage evolved.” [3, $p$. 4]. The great advantage in promoting cultural tourism activities, directly and indirectly dependent on the fruition of archaeological heritage, encapsulates the existence of a plethora of dimensions e.g. political, economic, social, cultural, educational, bio-physical, ecological and aesthetic, which currently characterize them. Therefore, governments seek to deploy an economic activity with its major feature involving the production of products with various dimensions and that, as such, proves an effective tool to capture the entire scope of benefits stemming from the cultural heritage and thus “...generating funding, educating the community and influencing policy.” [3, p. 5]. At present, cultural heritage management institutions largely and unanimously defend the idea that, if properly managed, cultural tourism may 
enable local and regional economic and socially sustainable development, providing the heritage host communities with important means and major motivations to protect and conserve their cultural archaeological heritage. The basic key to guaranteeing the success of such a tourism based protection and conservation strategy is the "...involvement and co-operation of local and/or indigenous community representatives, conservationists, tourism operators, property owners, policy makers, those preparing national development plans and site managers...” [3, p. 5]. Consequently, the economic challenge for local and regional cultural tourism based development strategies involves maximizing the advantages of tourism growth and to minimize and offset the costs of the impacts resulting while securing future local and regional growth. Convincing the population and stakeholders that investing in heritage protection and conservation is a worthwhile decision essentially requires clearly demonstrating the gains and benefits and necessarily encompassing a precise definition of what constitutes cultural heritage benefits (and therefore values) and the existence of methodologies to adequately assess the entire extent of cultural benefits not only qualitatively but also and especially quantitatively. What would be ideal, in fact, would be a clear cultural benefits definition further complemented by a methodology quantifying all cultural benefits by means of a unique number measured in currency. A definition of cultural benefits plus the monetary measurement of the benefits would therefore establish two important tools to help in convincing stakeholders both to comply with heritage conservation and to engage with cultural heritage conservation activities respecting preservation. As they supply additional, clearer, and concrete information, the definition of benefits and the disclosure of the results of quantification tools decrease the uncertainty and risk of investment otherwise caused by the lack of information available to stakeholders. Based on the hypogeum necropolis case, this paper focuses on contributing to the discussion around the value of archaeological heritage through the lens of an economist. The path taken to achieve this main goal included three underlying objectives. The first involves contributing towards clarifying the archaeological cultural benefits concept by demonstrating and discussing its holistic complexity. The second encapsulates the valuation of those benefits by demonstrating how they are susceptible to capture by means of a single variable measured in monetary units. And, finally, the third objective is to better explain just how such an archaeological cultural benefit variable might be embedded into both cultural heritage management practices and appraisals of cultural projects. The paper is organised as follows. Section 2 discusses the multidimensional characteristics of archaeological goods and ends with a holistic definition of the archaeological social-economic benefit concept. Section 3 discusses how important preference based neoclassical consumer theory may be to defining, ranking, and assessing multidimensional individual preferences for archaeological services by means of a single amount of money. We put forward a general theoretical dual consumer model alongside the economic money measures for the archaeological heritage preferences defined. Section 4 covers the preference-based techniques used to capture the plethora of economic and social values of archaeological goods by means of surveying the empirical literature on the 
subject. In section 5, we discuss the importance of the economic use value variable to improving archaeological remains conservation and preservation strategies in addition to establishing the conditions to provide host communities with the means to generate economic and social benefits that provide the foundations for sustainably boosting local and regional development. Finally, we present our conclusions.

\section{The Multidimensional Characteristics of Archaeological Remains: merit, public, and private goods}

Archaeological remains include work tools, weapons, domestic utensils, cloths, ornaments, settlements, fortifications, ancient hydraulic structures, ancient agricultural fields, roads, mining pits and workshops, ancient burial grounds and various burial and religious structures, drawing and inscriptions carved into individual stones and cliffs, architectural monuments, and sunk ships and cargos [http://encyclopedia2.thefreedictionary.com/Archaeological+Remains. Last access: $30^{\text {th }}$ November 2015]. The hypogeum necropolis recently discovered in the Alentejo includes a vast set of graves with underground burial chambers running well below the surface area. Skeletons and various objects in stone and bone were also recovered with the archaeologists responsible for the excavation emphatically classifying the archaeological discovery as "very important to the history of the region" and therefore correspondingly worth preservation. From an economic perspective, such archaeological remains are perceived as to be non-homogeneous capital resources in that they enable the generation of different sets of different cultural services, including diverse cultural activities and diverse cultural functions that thus configure the supply side of archaeological goods. These may be used for example as stock for disclosure by means of a museum and/or as inputs which, when combined with others, enable the production of additional cultural goods or services including for instance cultural routes, cultural workshops, or cultural shows. When individuals reveal their preferences for increasing the cultural stock and supply flows through expressing the maximum they are willing to pay, this constitutes the demand side for cultural archaeological goods. Individuals, however, often experience great difficulty in recognising and expressing their real willingness to pay for these type of products. Such inability derives from the particular economic characteristics of archaeological remains which prevent the existence of private markets and, therefore, of any well determined market supply and demand curves and their corresponding determination of the efficient quantity and price that would maximize the host community welfare. We made recourse to Mazzanti's conceptual framework [5] to explain how intricate the economic definition of archaeological remains as cultural heritage goods actually proves. Mazzanti thus explains how the existence of market failures prevents any efficient allocation of cultural heritage services and goods and rooted in the multi-dimensional, multi-attribute, and multi-valued characteristics of heritage cultural resources that endow them with multi-dimensionality flowing from their status as merit goods. 


\section{Archaeological Remains as Merit Goods}

The concept of merit good was originally defined by Musgrave [6], [7]. Throsby and Withers [8], Cwi [9] and Netzer [10] further apply it to characterize the supply of cultural goods. A merit good proves identifiable by one or by all of the following characteristics [11]: individuals express multi-level preferences for them; community preferences exist; merit goods suffer from information or formation deficits whether from the supply or the demand side; and they experience distributive paternalism. These merit good characteristics prevent the demand and supply of cultural heritage services taking place according to the traditional means of competitive private markets. And while markets enabling the supplying of merit goods do exist, common market supply and demand Marshallian functions would prove insufficient for achieving the market quantity and price equilibrium compatible with the socially efficient level of consumption (or fruition). Such market incapability is directly related with the specific characteristics of cultural heritage service merit goods, thus hindering the Marshallian supply and demand functions from expressing the entire scope of consumer and supplier preferences for archaeological goods. The absence of markets generates difficulties for actors striving to efficiently choose their best options for maximizing their own welfare. For example, local governments and politicians become sceptical over the social and political good of deviating scarce financial resources to finance the preservation of archaeological remains without at least knowing the local population's exact perceptions. Private stakeholders and entrepreneurs fear - and mostly even ignore the possibility -investing in cultural heritage conservation due to uncertainty and the strict preservation regulatory norms in effect that may well represent obstacles to the maximization of private profits. Both on the demand and supply market sides, several issues form the basis of cultural heritage market failures. On the demand side, individuals fail to clearly express their preferences in the form of their maximum willingness to pay for the remains, due to a lack of information and existing individual, community, paternalistic, and inter-generational multipreferences. Such inability in expressing the plethora of preferences for culture proves the main obstacle to constructing an aggregate demand function for the necropolis, thus turning the assessment of current and future consumer values for such goods through markets into a hard, and sometimes impossible, task. One of the consequences of such a lack of information makes common individuals ordinarily ignore the existence of cultural heritage or, when acknowledging it, they remain unable to recognise its importance or value as cultural heritage where not exposed to additional informative cultural sessions. Others, although able to perceive the importance of archaeological goods as cultural heritage, may however not be able to express clear preferences for them. That is, while perceiving the existence of the cultural good, individuals may ultimately fail in stating their willingness to pay an amount adequate to tackling the multiexternalities arising from the consumption of the good simply due to their inability to recognize them. Still others fail to express their real willingness to pay due to the absence of personal budget constraints as happens with researchers, experts and students. These social groups experience high cultural preferences 
when visiting museums, archaeological sites, libraries, and exhibitions but are unable to express their economic preference associated with a particular amount of money as they deem archaeological remains priceless. Another consequence associated with the lack of information incorporates how the consumer's net private benefit associated with archaeology fruition does not get fully recognized at the time of the consumption. Even if consumers were aware of the true costs they have to support to access and enjoy the archaeological remains - measured, for instance, on the time spent on visiting -, they would however fail to recognize its full worth, that is, they fail in capturing the real individual social value of the cultural good. In fact, they are not capable of capturing the entire cultural benefits in terms of more knowledge and more education, better current and/or future jobs, higher salaries, or status or skills which might be associated with their own self-cultural improvement. Other problem behind the existence of unclear preferences relate to a considerable time lag between the cultural enjoyment and the concrete manifestation and overall appraisal of the positive effects to cultural exposure. The entire private benefits from enjoying archaeological remains may only occur some years after the original consumption with this contributing to the individual's lack of perception concerning the benefits associated with recourse to archaeological cultural services. A paternalistic attitude towards archaeological goods [5] also needs considering given how this may prevent the wide appeal and spread of archaeological markets. Less informed individuals cannot appreciate and thus enhance archaeological remains in the same way as experts do which is mainly due to the generally poor perception they have of archaeology. However, citizens are not to be blamed for not knowing, admiring, or valuing those archaeological remains experts consider of inestimable scientific value. Population's perception flaw lies fundamentally in the absence, or the inadequacy, of the promotional strategies cultural agents should be compelled to promote. Without appropriate promotional strategies, a non-expert will experience great difficulty in perceiving (and admiring) a recently discovered hypogeum necropolis with its skeletons and graves whenever not sufficiently contextualized in space and history. If this non-expert the task of deciding on his/her own whether or not it is worth spending scarce community resources on preserving and/or conserving the hypogeum necropolis without any additional information would be the same as condemning it to destruction or obliteration, particularly in cases where attributes such as monumentality or easy traces of beauty, are absent. On the other hand, leaving decisions only to experts like archaeologists or academics would entail increasing government involvement, and the allocation of massive financial resources to cultural preservation and conservation policies. Politicians may also suffer with the absence of complete and credible information about real population perceptions and attitudes towards the subject; they may see their re-election compromised should they decide to favour heritage patrimony preservation. But despite the difficulty experienced by non-experts to recognise and interpret the value of the archaeological heritage, most communities do however generally recognise that archaeological remains hosted in their own territories represent testimonies of their own culture and history. Therefore they agree with 
preservation policies to the point of being willing to sacrifice something towards these goals because preservation may enforce community self-esteem, social cohesion, retention of population, more education and wellbeing. They sometimes do also recognise that such patrimony may serve to generate economic benefits for the local society, including jobs, new businesses and infrastructures, wealth and rising taxation returns. Therefore, the combining of expert paternalism with community preferences for archaeological cultural heritage might perhaps enable the preservation of that archaeological patrimony that would otherwise be destroyed should its future fate be left only to individual single preferences. Other consequence of the lack of a demand function, derive from the prices that may sometimes be charged to consumers, should the archaeological services be privatised. In order to prove profitable while totally or partially ignoring the demand for cultural heritage, the price charged to cover the marginal costs of supplying the preserved patrimony would have to increase to such levels thus turning the cultural goods unaffordable to low income families. This would greatly contribute to a sharp decrease in the demand for a good often viewed as non-essential, particularly in low income economies. From the supply side, there also several issues mostly related with the lack of information due to the absence of any market for the hypogeum necropolis which prevent private cultural service producers from capturing real consumers' willingness to pay for cultural fruition. Private actors cannot ascertain the Marshallian demand function because this neo-classical economic instrument is incapable of reflecting the entire extent of consumer multi-preferences for cultural heritage services. As a consequence, when private producers attempt to set the prices charged for cultural services, they have no way of knowing to what extent these are compatible with the real consumer willingness to pay for cultural goods. Where private producers experience high average production costs because the fixed costs of cultural heritage preservation are high, the price they charge to guarantee the efficient economic profitability of the cultural heritage preservation business may effectively price it far above the consumer's willingness to pay for the level of cultural heritage supplied. As a consequence, consumers will not consume the cultural good, the private producer will go bankrupt and resulting in the loss of the cultural services and social and economic benefits it might otherwise generate. Even if there were producers possessing full information as the demand for archaeology, the efficient price they would charge for the sake of both efficiency and their own survival would still be far higher than the maximum amount consumers would be willing to pay. Being so, the market for cultural heritage services would be non-existent and thus with no efficient transactions taking place. Other market imperfections characterizing cultural markets include the existence of positive externalities associated with the direct and indirect usage (consumption) of cultural heritage. Nevertheless, such positive external benefits do not gain recognition as individuals are driven only by self-interest at the point of consumption i.e. someone who disregards archaeology and thus lacks the motivation to either visit or enjoy the archaeological knowledge will also prevent others with whom he/she has contact from benefiting indirectly from raising their level of culture in some way. As happens with other externality cases, the 
external benefit of archaeological knowledge usage is not likely to enter into the private decisions of buyers (users) and sellers, which, as a consequence, holds the true total archaeological benefit to be much greater - although insufficiently known - than the individual evaluations made. Where the provision of archaeological remains is calculated by free markets under the presence of such externalities, underconsumption and under-supply will result as shown in figure 1 . When consumers fail to recognise the positive externalities stemming from the consumption or usage of cultural goods, the market equilibrium is given by $\mathrm{E}^{*}$. However, when individuals perceive positive externalities, their true total marginal benefits would be returned by the curve $\mathrm{D}^{\mathrm{S}}$ (in the place of $\mathrm{D}$ ) and the new market equilibrium would be $\mathrm{E}^{* \mathrm{~S}}$.

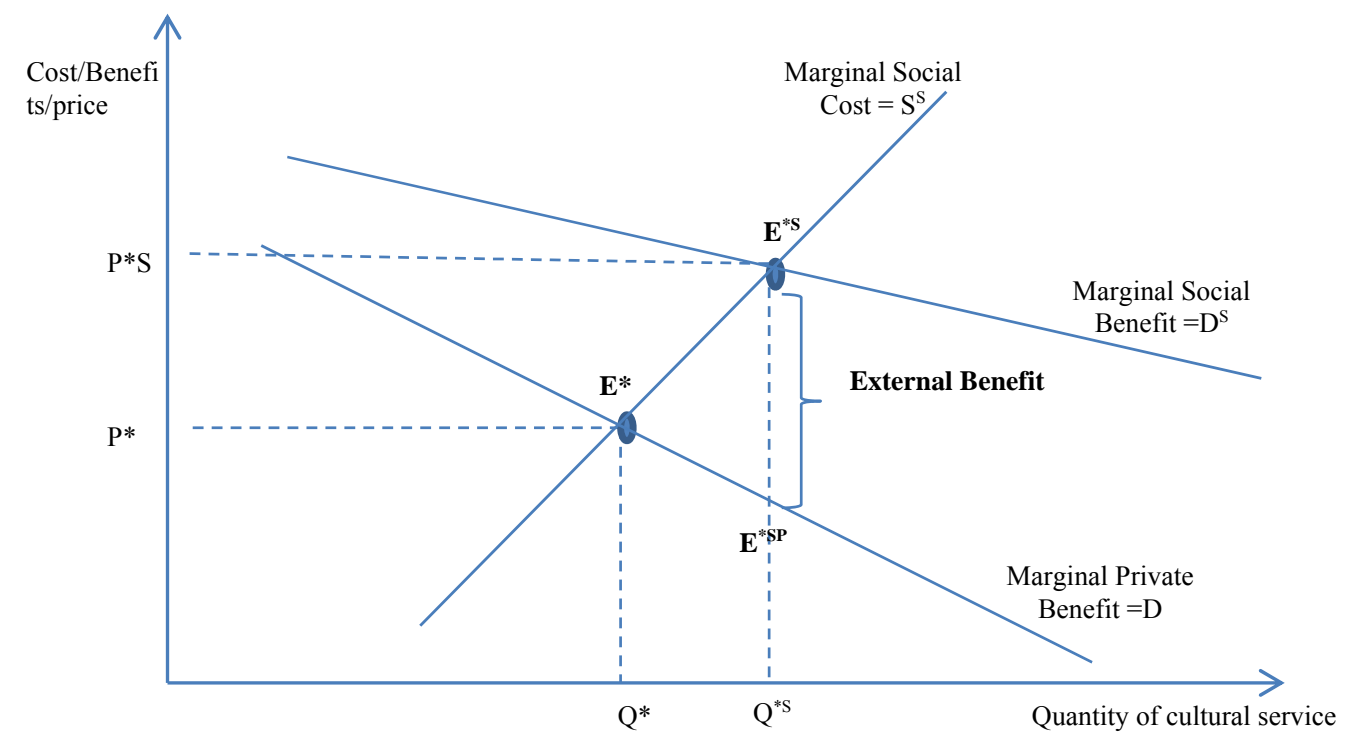

Figure 1: Archaeological markets: private and social efficient equilibrium; consumption externality

More cultural goods would be supplied at higher charges thus enabling suppliers to capture the true willingness to pay of individuals for $\mathrm{Q}^{* \mathrm{~S}}$. The non-internalisation of such cultural externalities is at the basis of under-consumption, under-supplying and under-pricing situations, thus making the entrepreneurs to fail in capturing the entire consumer's benefits of archaeological knowledge through markets. When markets fail, governments get called in to intervene by establishing the conditions necessary to ensuring increasing consumer demand and/or cultural supply. However, not all economic instruments prove able to achieve this in a cost-efficient way. Otherwise apparently common market-based forms of improving the supply side for some market good, such as setting a floor-price and thus providing incentives for private actors to enter the market even if potentially discouraging the already reluctant demand; or attributing a subsidy to reduce supply side costs, are not applicable to archaeological heritage services. An alternative to these would see, for instance, governments paying for additional costs that private owners might incur in increasing supply whilst simultaneously requesting individuals pay a user fee as one contribution towards financing the preservation costs. However, the problem with this market-supplyside policy incorporates the lack of information as the overall body of consumers would not take the 
initiative to increase demand for archaeological goods because they still cannot perceived their worth with the exception of archaeological experts and similar. This market-supply-side policy failure constitutes the reason some call for direct market-demand-side policy measures on the grounds these present the most efficient way of improving cultural heritage markets, and therefore social cultural interest. Nevertheless, and as happens with supply side policies, market demand based measures such as setting a price-ceiling to improve cultural demand, might not represent the most appropriate approach in the case of archaeological remains as there might be different markets for the same cultural heritage good, and not just one single market; or, alternatively, there may be no market whatsoever. The existence or nonexistence of markets ultimately depends on the intrinsic characteristics of each specific instance of archaeological remains and the types of uses society seeks to make of them. Pricing demand for archaeological heritage merit goods represents an obstacle to cultural heritage markets in general and may configure a difficult issue necessarily faced by private suppliers due to the existence of multi-preferences for cultural services which renders impossible to make any univocal relationship between some amount of supply and each individual's average maximum willingness to pay for it, as is commonly express through Marshallian demand functions. This is because individual's willing to pay does not refer to homogeneous preferences and therefore cultural benefits. In fact, some citizen may be willing to pay for heritage for direct use motives while another may express his/her willingness to pay for it for altruistic motives, only. Furthermore, providing the archaeological remains for a positive price as if they were common marketed goods, may also not amount to any socially efficient solution, the problem being to know what value should be charged in the presence of externalities and lack of information. Although setting a positive price for the fruition of cultural heritage is a difficult task, to set it equal to zero is not a good idea either from the preservation and conservation point of view. Setting the cultural heritage user price equal to zero may be interpreted by society as a sign of the inferiority or lack of overall value of the cultural heritage and this may definitely serve to dissuade individuals from using and enjoying it and thus preventing the production of the multi-benefits otherwise generated. Secondly, a user price set equal to zero may prove an incentive to the occurrence of negligent preservation and conservation practices, negligent fruition, acts of vandalism, and/or behaviours of the tragedy of the commons type. Ultimately, due to the impossibility of establishing any market to efficiently allocate archaeological heritage goods due to their multi-dimensional characteristics stemming from their merit-good nature, it would seem that the most appropriate way of improving social welfare involves improving the public instead of the private archaeological heritage based cultural services and their respective supply and demand through disclosing their existence to potential users, that is the community. Supporting an adequate cultural heritage strategy, with its aim focused not only on the preservation and guardianship of cultural patrimony but also its dynamic conservation through different publicity and promotional means, would enable stakeholders and 
communities to appraise the entire cultural benefits (both private and social) they might feasibly attain and while consistently expressing their preferences.

\section{The Multi-dimensional, Multi-attribute and Multi-valued Natures of Archaeological Remains}

In the section above, we discuss why archaeological remains, including the hypogeum necropolis, as cultural heritage constitute a non-homogeneous capital economic resource and a merit good. A merit good is defined and evaluated through the set of its associated cultural functions and cultural attributes with its disclosure to potential users the best means of generating additional private and social benefits and maximizing social welfare. The hypogeum necropolis promotional and awareness raising strategy may itself be classified as a merit good with its main characteristic encapsulating the potential to make-newthings-happen [5], which also drive the increase in the archaeological supply. This thus provides the basic conditions for promoting culture based institutions and, simultaneously, local sustainable development, where the former serve as input resources for the latter while additionally incentivising the expansion of present and future cultural demand and supply, therefore promoting recourse to cultural goods by the community. Disclosing cultural heritage strategies in fact represents “... the necessary pre-condition for the possibility of expressing a (future) Willingness to Pay (WTP), associated to cultural (use and non-use) consumption." [5, p. 536], because this intrinsically deals “...with inter and infra-generational scenarios where, at a given time, merit good policies provide the basis for future consumption, that is they provide the basis for the development of cultural institutions." [5, p. 536-537]. In such situations, where there exists archaeological cultural stock of sufficient importance to justify its disclosure to the community by means of some preservation public policy, by far the most effective way of tackling the archaeological benefits issue through means of quantitative valuation involves applying a new and broader benefit typology to enable the definition and incorporation of all the values (benefits) into the preservation and conservation strategy. Such a typology is key to the valorization process in that it breaks the significance down into the different kinds of cultural preferences or values thus enabling archaeological experts, students, citizens, local and regional communities, government entities, firms, international visitors and other stakeholders to clearly identify, classify, compare, and rank the set of cultural heritage services and thus returning a more effective ordering of preferences. Different scholars and organizations have been working to define a typology that embraces the entire different benefits and values arising from cultural goods in general. However, the complex network of fuzzy benefits and values related with historic merit, artistic merit, community values, altruistic or intrinsic values, or merely euros, that these type of goods potentially generates, and the differences between epistemology and the modes of expression and measurement of such benefits or the values applied by for example archaeologists, sociologists and economists (see Table 1 for some examples), renders cultural valuation a complex and sometimes subjective and contingent task and therefore correspondingly making difficult any ready comparability or translatability of the entire cloud of cultural values. 
Table 1 Some Cultural Value Typologies

\begin{tabular}{|c|c|c|c|}
\hline Lipe [12] & Frey [13] & English Heritage [14] & Burra Charter [15] \\
\hline Economic & Monetary & Cultural & Aesthetic \\
\hline Aesthetic & Option & Educational and Academic & Historic \\
\hline $\begin{array}{l}\text { Associative- } \\
\text { Symbolic }\end{array}$ & Existence & Economic & Scientific \\
\hline Informational & Bequest & Resource & $\begin{array}{c}\text { Social(including spiritual, political, national, } \\
\text { other cultural) }\end{array}$ \\
\hline & Prestige & Recreational & \\
\hline & Educational & Aesthetic & \\
\hline
\end{tabular}

We may apply our hypogeum necropolis as a good example of the aforementioned complexity, which interrelates with the multidimensionality of benefits and values and the set of issues potentially arising out of decisions over implementing preservation and conservation strategies and disclosing the new cultural heritage for local development. Following the discovery of the hypogeum necropolis, what is now to be done? Should experts consider the discovery as sufficiently important as to deserve preservation on the grounds of paternalism, the hypogeum will subsequently not be destroyed and thus configuring an increase to the stock of heritage capital and cultural supply, which will then enhance community welfare. Next, decisions must be taken by local government entities and/or the private owner of the land hosting the archaeological remains: might the necropolis simply be preserved or does it also need to become the main focus of some specific conservation policy? Preservation and conservation are themselves examples of new cultural services and functions displayed by the cultural attributes of archaeological remains and that will enhance society through several use and non-use values. Use-values interrelate with individual visits to the site either by inhabitants or by tourists for the purpose of enjoying the necropolis and generating flows of direct-use values to visitors; or, they may alternatively be from students or researchers and thus generating flows of direct education and research use values. Non-use individual and/or community values stem from inter-generational altruism, development related altruism, ethical, and/or religious motives. The next decision encapsulates the design of the preservation/conservation strategy type then subject to implementation. Should the site of the hypogeum necropolis be preserved only for public visits, education and/or research, how and where does it get disclosed to society? Should it be simply demarcated and fenced off to control some of the eventual damage potentially caused by visitor, without any further conservation intervention? Or should the site be targeted in such a way as to provide visitants with additional information about the remains and the excavation work? Or should the archaeological patrimony instead be extracted from its site of its discovery and relocated for disclosure in some cultural institution such as a museum? In the first case, the necropolis represents mere new capital heritage stock that gets used/enjoyed as such and therefore expanding the supply of culture. In the second and third cases, the necropolis constitutes capital heritage stock applied as input in combination with others - cultural and non-cultural -, thus giving rise to new cultural products and further expanding culture supply. There are many different means to disclose archaeological cultural heritage. Some are more complex and sophisticated than others with the choice always dependent on the main aims set for the conservation strategy. Disclosing the hypogeum necropolis and burial remains on site simply surrounded by a fence 
and without any additional associated information by no means constitutes the simplest way of achieving this. However should posters be placed on site containing information about the remains and the background to the excavation works, we are already somewhat valuing the archaeological stock and therefore improving the educational direct use-benefits. The valorisation and disclosing strategy for the remains may be still further improved should new cultural functions or infrastructures be produced for example, an interpretation centre or an on-site museum. These more complex infrastructures might integrated into a larger cultural park for instance, which might include the natural landscape and other cultural activities (e.g. exhibitions, concerts, archaeological related workshops, interactive hardware and software, or non-cultural) with other non-cultural hypogeum necropolis related activities (e.g. bars, souvenirs shops, restaurants or regional products). Some even more integrated preservation and conservation strategies may extend to more specific touristic related items, such as thematic routes or establishing a new brand label that would associate the region and the products it produces with the archaeological remains. We may easily conclude that these more complex preservation and conservation strategies will enhance, directly and indirectly, the production of different sets of new cultural goods, new cultural functions and institutions, new economic products and new businesses. Indirectly, more complex archaeological preservation and conservation strategies provide the point-of-departure to nurturing more skilled and non-skilled employment, reinforcing the local economic base, boosting local wealth and thus enlarging the income tax base, strengthening community and preventing the migration of inhabitants. There is however some issues that may constitute future obstacles to any successful integrated preservation strategy, which relate with property rights. In the case of our hypogeum necropolis, for example, additional questions need answering over just who owns the archaeological remains. If they belong to, for instance, a private property, should they be considered public or private goods? Can a private good, lying in a private property, be managed by a public institution due to its merit nature i.e. when stakeholders assume that the preservation and conservation functions belong exclusively to the local government for reasons directly related with the merit good nature of the burial remains, will the in loco implementation of the conservation strategy be a public, a private or a public-private responsibility? Concerning other issues such as who is going to monitor all of the steps that make up a conservation strategy, are these an exclusive obligation of the local government, of the local community and stakeholders or do all of them instead hold responsibility? And just who pays for all this? Should the preservation and conservation strategy be exclusively paid for by subsidies or taxes, or should every actor shoulder part of the financial burden due to the plethora of benefits the strategy may create eventually return and reaching far beyond the minimum direct use-benefits generated by preservation alone through means of a single protection fence? 


\section{The Concept of Cultural Heritage: A New Typology of the Holistic Type}

The co-existence of different categories of archaeological cultural values, whether economic, historical, spiritual, political, educational, aesthetic, artistic, scientific or social and which stem from preservation and conservation strategies, demands recourse to a typology able to explicitly recognize and integrally incorporate such variety and complexity whilst also providing a framework for generating the assessment of the accumulative and overall value of these respective different categories. The Mazzantti typology framework [5] seems to appropriately respond to all the former issues and was therefore applied in this paper. The Mazzanti conceptual framework characterizes cultural goods and their disclosure strategy as multi-dimensional and multi-attribute goods, and multi-value resources, where the multi-dimensionality derives from their categorisation as merit goods, public goods, and/or mixed goods as already discussed in the previous section. Based on the Mazzantti typology, the hypogeum necropolis and its burial remains are multi-dimensional, multi-attribute and multi-value cultural resources in accordance with their status as cultural heritage capital goods. Their multidimensionality arises out of the merit good characteristics of the necropolis and the related preservation and conservation program. The hypogeum necropolis - viewed as a non-homogeneous capital economic good and merit good -, and its preservation and conservation program - viewed as a merit good cultural policy -, make up part of a meta-scenario characterized by the existence of a network of private and community intra-preferences, use and non-use preferences, and intergenerational preferences. The multi-dimensional nature enables the definition of the pre-conditions necessary for individuals to express their own willingness to pay for the fruition of the cultural good and thus generating self-use and non-use benefits in the long run. The hypogeum necropolis is multi-attributed i.e. as a capital resource, and correspondingly capable of underpinning new cultural institutions, new cultural goods, and the expansion of archaeological demand and supply. Its multi-attribute characteristics include two multi-attribute sub-sets: the cultural services and the cultural functions sub-sets. The former relates with consumptive and non-consumptive fruition while the latter only includes the non-use values. The existence of multi-values interrelates with these hypogeum necropolis multi-attribute characteristics and therefore classified as both internal and external. The internal values include the components of the neo-classical total economic value (TEV) concept [17], [18] which equals the sum of the following different value components: non-consumptive direct-use value; indirect-use values; option-value; and non-use value (existence; paternalistic; legacy). in turn, direct-use value consists of the benefits stemming from directly visiting the site and benefitting from the associated cultural services and functions for cultural and recreational purposes e.g. museum visits, participation in workshops or in thematic routes; this value category also includes the vicarious-use-value category which addresses the satisfaction some individuals may experience from pictures, books, archaeological artefacts or broadcasts based on the hypogeum necropolis even when never actually able to visit the site itself. Indirect-use values are benefits indirectly experienced by citizens when consuming the new cultural services and institutions generated by 
the discovery and preservation of the hypogeum necropolis e.g. tourism activities incorporating the hypogeum necropolis as a factor of production or the consumption of new local products produced within the framework of the archaeological discovery. Citizen enjoyment, through the consumption of other economic services enabled by the conservation strategy e.g. restaurants, souvenir shops, bars, concerts, lodging, etc. also represent indirect-use values. Citizens may also enjoy how their own self-contribution and self-commitment to preservation and conservation strategies in the present help in guaranteeing the archaeological remains will not be destroyed, thus conserving the option for self-using it directly or indirectly in the future and in keeping with their preferences. This is the so called option-value that proves very similar to individual value stemming from contracting insurance policies. Both direct-use and optionvalues belong to the broader category of use-values. Non-use value (bequest and existence) comprises the entire extent of the sociocultural values such as the historical, symbolic, political, and social importance individuals may attribute on knowing that the collective memory associated with the hypogeum necropolis will be preserved irrespective of current or future uses. The bequest-benefits reflect altruistic citizen satisfaction from knowing that the archaeological knowledge will be conserved for the benefit of their heirs and the local community. The bequest-value also reflects the expectations people place on the preservation and conservation strategy as regards the potential improvements to the local economy. This form of value reflects the social benefits of preserving and conserving the hypogeum necropolis by deploying it as a form of capital. This enables the capturing of the collective perception on the additional cultural services that may be provided to citizens and their capability to generate employment, investments, new infrastructures, new business, wealth (and therefore wellbeing), to strengthen the local community's image and self-esteem. Existence-values reflect citizen satisfaction stemming from the mere existence of the archaeological capital even though they themselves know they will not experience it either directly or indirectly whether because they physically cannot or due a lack of any appreciation for archaeology. Existence, paternalistic, or bequest-values are all non-use values (also referred to as passiveuse benefits) and include the entire range of intangible social benefits some individual may gain from simply knowing that the archaeological rescue knowledge exists and persists, independent of whether personally self-used. That is, economists describe the non-use values as emanating from the merit good qualities of the cultural good. Hence, non-use values cannot be captured by common cultural heritage markets as these do not exist and therefore rarely assessed and/or applied as a tool for improving the process of more efficiently choosing from among the competing alternative preservation and conservation programs. Non-use values constitute an equivalent way of weighing up the socio-cultural values sociologists, politicians, or researchers describe [16] as they include the artistic, scientific and historical values; the cultural/symbolic/political values broadly applied to build cultural affiliations in the present and thus enforcing local culture, the sense of community and pride in it; and the social values, including "place attachment" aspect, strengthening social local cohesion and community identity. External values 
relate to economic impact factors [19]. They include the economic benefits generated by the implementation of the preservation and conservation program e.g. direct expenditure (investment) on the project and the indirect expenditures induced by both the suppliers and those making up demand for the cultural project. For example, when considering a cultural event project such as a musical performance held on the site of the archaeological discovery, the direct external benefits generated by this should include the direct expenditure and the benefits resulting to the musicians and technicians engaged in the project and the suppliers of the new cultural product (the event's inputs i.e. the concert held on the discovery site). In turn, the latter will indirectly generate a flow of additional indirect economic benefits by spending part of their revenues on supplying the new cultural good and service. The audience attending the event will also spend money on the entrance fee, transport costs, hotels, meals, consuming other local cultural services, and purchasing other local products. Therefore, bundles of cultural actions (e.g. the preservation and conservation of the hypogeum necropolis) associated with bundles of differentiated cultural projects (e.g. the musical concert) trigger a multiplier economic process that reaches far beyond the direct expenditure incurred in supplying the musical concert: ultimately, such flows of economic benefits improve local wealth creation; create more employment opportunities for both skilled and nonskilled labour; reinforce local markets; liberate additional wealth to finance the public sector; reinforce the sense of community and self-esteem; and enforce the social-network of connections. Table 2 summarizes this network of cultural functions, attributes, and benefits (values) associated with applying the hypogeum necropolis as a cultural stock of capital alongside some relevant cultural activities that should also become part of the preservation and conservation strategy and program. In Table 2, the internal values i.e. social, historical, political, non-marketed direct and indirect-use values, and non-use values, become integrated into the external values i.e. economic values including employment, income, etc., instead of describing them separately.

\section{The Economics of Capturing the Multi-Dimension Value of Archaeological Remains}

In the sections above, we discussed the archaeological heritage characteristics underlying the different nature of the benefits potentially generated to individuals and communities, the scope of benefits depending on the types of uses and fruitions that society and individuals may make of them. Cultural heritage therefore proves to be a most valuable asset to society even if its value is not entirely recognised by all for the reasons discussed above. However, if there were a single variable for this purpose i.e. able

Table 2 Breaking down the Multi-Dimension, Multi-Functions, Multi-Attributes and Multi-Values of the hypogeum necropolis (as capital stock) and of some feasible preservation and conservation programs

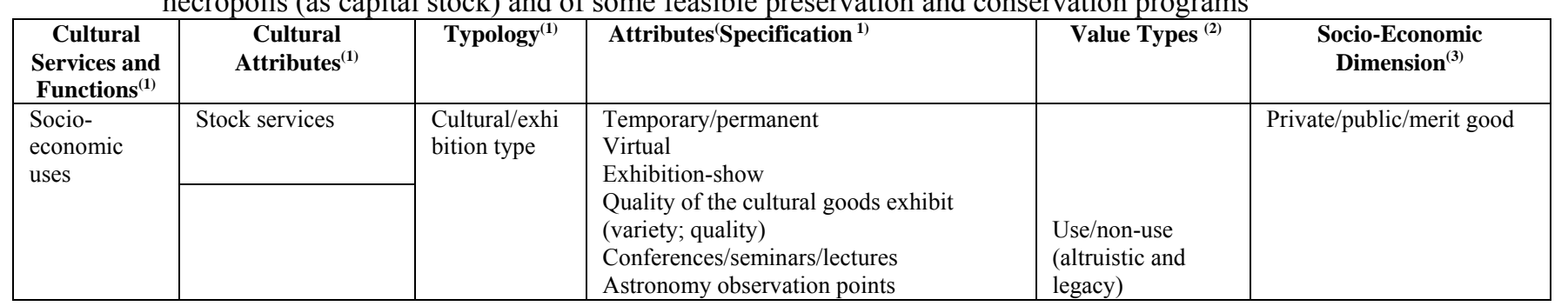




\begin{tabular}{|c|c|c|c|c|c|}
\hline & $\begin{array}{l}\text { As input to produce } \\
\text { additional cultural } \\
\text { goods and services, } \\
\text { and other cultural } \\
\text { goods indirectly } \\
\text { related with them }\end{array}$ & $\begin{array}{l}\text { Commercial; } \\
\text { Tourism; } \\
\text { Educational; } \\
\text { Recreational; }\end{array}$ & $\begin{array}{l}\text { Shows of local products with necropolis } \\
\text { based labels; } \\
\text { Experimental archaeology workshops } \\
\text { Bars; restaurants; museum shops; other } \\
\text { shops (sale of necropolis based local } \\
\text { products); } \\
\text { Routes; exhibition-shows; may be } \\
\text { associated with cultural attributes } \\
\text { Assistance and facilities: school projects; } \\
\text { May be associated with cultural attributes: } \\
\text { interrelated with recreational technologies }\end{array}$ & $\begin{array}{l}\text { Use } \\
\text { Use/non-use - } \\
\text { (altruistic and } \\
\text { legacy) } \\
\text { Use/non-use } \\
\text { (altruistic) } \\
\text { Use/non-use } \\
\text { (altruistic) }\end{array}$ & $\begin{array}{l}\text { Private/public } \\
\text { Private; } \\
\text { merit good } \\
\text { Private, public, } \\
\text { merit } \\
\text { Private/public good }\end{array}$ \\
\hline Conservation & Conservation; & & & $\begin{array}{l}\text { Inter-generational: } \\
\text { existence non-use } \\
\text { value; }\end{array}$ & $\begin{array}{l}\text { Merit good/public } \\
\text { good/social value }\end{array}$ \\
\hline $\begin{array}{l}\text { Public } \\
\text { guardianship }\end{array}$ & $\begin{array}{l}\text { Safeguarding of } \\
\text { heritage; } \\
\text { Property right } \\
\text { definition; } \\
\text { Stewardship }\end{array}$ & & & $\begin{array}{l}\text { Infra/inter } \\
\text { generational } \\
\text { existence non-use } \\
\text { value }\end{array}$ & $\begin{array}{l}\text { Merit good/pure public } \\
\text { good/social value }\end{array}$ \\
\hline
\end{tabular}

Source: Adapted from [5] Caption: (1) Based on the Mazazanti classification [5]; (2) based on TEV classification of use-values (direct use such as on site visits, and indirect use such as bars, shopping, concerts, etc.) and non-use values (existence or intrinsic-values; altruistic-values; legacy-values);(3) based on the existence/non-absence of market failures depending on the characteristics of each type of cultural good; conditioning the existence/ non-existence of markets.

to quantify the plethora of benefits stemming from cultural heritage conservation and preservation strategies for local sustainable development, this would certain constitute a useful tool enabling politicians to take more efficient and socially fair decisions. In this section, we describe a general neo-classical preference based model built to quantitatively assess, in currency terms, the multi-dimensional values potentially stemmed from the multi-attributes of preserving and conserving archaeological heritage. More specifically, we aim to assess the internal Archaeological Preservation and Conservation Program (APCP)'s benefits i.e. the direct and indirect use-values, the option value, and the non-use value. The assessment of other aspects, such as external economic benefits (quantitatively) and social benefits (qualitatively), fall beyond the scope of this paper. The former, new employment, more wealth, more business opportunities for example, are susceptible to assessment by means of market based methodologies, such as direct valuation through market prices, cost-benefit analysis of the preservation and conservation programs, input-output analysis or general equilibrium models. The latter, where social benefits and community concerns and preferences are included, for example benefits stemming from uses of the land hosting the remains, property rights issues, the community identity, lifestyles, or livelihoods, may also be identified and evaluated through other approaches, such as the social impact assessment methodology [20]. However, social impact assessments only achieve this in qualitative and therefore rather vague terms and proving problematic whenever the goal involves quantifying the magnitudes of the social impacts and monitoring them over the course of time. The utilitarian approach undoubtedly brings 
added value to the social-economic evaluation and assessment methodologies for the impacts stemming from the implementation of APCPs in practice given that this enables the capturing of the internal benefits stemming from their merit good characteristics that markets are otherwise unable to reveal. As discussed in the section above, people may enjoy archaeology both directly and indirectly in many different ways and for self-interested reasons, thus getting different use and/or non-use benefits. Such a myriad of benefits may be assessed through the neo-classical citizen's willingness to pay (WTP) to secure them measure. This economic measure of value proves much powerful and relevantly useful than a mere qualitative attitudinal statement in which people often declare how they "care about culture" even while in practice they do not actually feel able to sacrifice anything to support it. The declaration of some WTP forces individuals to take into account the fact they themselves are being asked to sacrifice some of their limited income (or time) to secure some cultural strategy that will change their own level of wellbeing. The utilitarian based approach to evaluation therefore ensures the tackling of the multidimensional forms of the value to archaeological remains by enabling their assessment through changes in citizen welfare levels motivated by an increase in cultural supply arising out of the archaeological conservation strategy. Such changes may be assessed either by means of individual preference functions or individual budget constraints in the same way the economic value of marketed goods gets assessed i.e. through the utilitarian compensated and equivalent money measures defined by Hicks [21] and Kaldor [22]. Based on the Mäller's theory of choice and welfare under quantity [23], [24] we here assess the changes in welfare stemming from changes in the quantity of archaeological goods supplied for some APCPs by applying the same economic measures that were originally defined to measure changes in welfare associated with changes in market prices [25], [26], [27]. We begin with the definition of the "total economic value of archaeological remains" concept as the amount of money individuals (or society) would pay (or be paid) to be as well off with the APCP as without it. The utilitarian theoretical model applied to derive the economic measures for changes in individual welfare due to changes in the supply of archaeological cultural goods is as follows.

\section{Measures to assess changes in individual welfare through individual utility function}

Let $U(x, q)$ be a well-behaved utility function of some individual affected by some APCP where $U$ denotes the level of utility (satisfaction, well-being) of each individual; $\boldsymbol{x}$ is a vector of marketed goods; and $\boldsymbol{q}$ is a vector of non-marketed archaeological goods. The individual wants to choose the optimal quantity $\boldsymbol{x}^{*}$ that maximizes his/her utility whilst constrained by his/her budget $\sum_{i} p_{i} x_{i}=m_{i}$ where $p_{i}$ is the market price of the $i$ marketed good belonging to $x$. The solution for the maximizing problem is the set of the individual's ordinary demand functions for the market goods denoted $\boldsymbol{x}^{*}=\boldsymbol{g}(\boldsymbol{p}, \boldsymbol{q}, \boldsymbol{m})$. Substituting the ordinary demand functions in the individual utility function, we attain the individual's indirect utility function, denoted $\mathrm{d} U(\boldsymbol{x}, \boldsymbol{q})=\varphi(\boldsymbol{p}, \boldsymbol{q}, \boldsymbol{m})=U[\boldsymbol{g}(\boldsymbol{p}, \mathbf{q}, \boldsymbol{m}) ; \boldsymbol{q}]$, which represents the set of maximum utility (or well-being) levels the individual can benefit from given his/her utility function 
and budget restriction. The individual monetary measure for changes in $\boldsymbol{q}$ represents the change in the individual's utility from the initial archaeological supply state $q^{0}$ to the final archaeological supply $q^{1}$, with prices and income kept constant at the initial state. Should the archaeological supply change be positive (the discovery of the necropolis and the implementation of the program increase the supply of cultural heritage directly and indirectly; therefore, given the "more is better" consumer well-behaviour preferences property, an increase in the individual utility level, and therefore of his/her welfare following the supply increasing, is to be expected) i.e. if $\mathrm{q}^{1}>\mathrm{q}^{0}$ then individual utility will rise by $\varphi^{1}\left(p^{0}, q^{1}, m^{0}\right)-\varphi^{0}\left(p^{0}, q^{0}, m^{0}\right)$. Such positive change in individual utility undergoes translation into monetary units through two welfare measures. These welfare measures applied to non-market transacted objects of choice, as is the case with ecosystem services, were first proposed by Mäler [23, 24] as an extension of the standard theory of welfare measurement related to market price changes formulated by Hicks [21]. The first measure is the maximum amount of money the individual is willing to pay to secure the right to be exposed to additional cultural supply stemming from the APCP i.e. the Willingness to Pay Compensated $\left(\mathrm{WTP}^{\mathrm{C}}\right)$ money measure and estimated by the equation $\varphi^{1}\left(p^{0}, q^{1}, m^{0}-W T P^{C}\right)=\varphi^{0}\left(p^{0}, q^{0}, m^{0}\right)$. The second measure constitutes the minimum amount of money each individual is willing to receive to make him/her give up on the cultural supply improvement i.e. the amount of money the individual wants to receive to make him/her as satisfied as he/she would be following the cultural supply improvement. This is the Willingness to Accept Equivalent $\left(\mathrm{WTA}^{\mathrm{E}}\right)$ money measure, and estimated through the indirect utility function by the equation $\varphi^{1}\left(p^{0}, q^{1}, m^{0}\right)=\varphi^{0}\left(p^{0}, q^{0}, m^{0}+W T A^{E}\right)$. However, it is impossible to ascertain the individual's indirect utility functions because individual utility preferences cannot be empirically accessed; therefore economists are unable to estimate the two measures as defined through the indirect utility functions. To overcome this restriction, economists make use of the theoretical duality between the unknown indirect utility function and the known individual expenditure function denoted as $e(p, q, U)$. This last function represents the minimum expenses (the individual's budget restriction) incurred by the individual to purchase a bundle of quantities of marketed products that make him/her satisfy a previously set level of utility. Due to the aforementioned duality, the equality $e(p, q, U)=$ $p h(p, q, U)=m$ is true, and $\boldsymbol{h}(\boldsymbol{p}, \boldsymbol{q}, \boldsymbol{U})$ represents the vector of the individual's compensated demand functions for the marketed products $\mathbf{X}$.

\section{Changes in an individual's welfare assessed by his/her budget constraints}

Let us once more consider the well-behaved utility function $U(\boldsymbol{x}, \boldsymbol{q})$ applied in the consumer maximizing problem above. Now, the individual seeks to choose the cheapest $\boldsymbol{x}^{*}$ to attain a previous level of utility set at $\overline{\mathrm{U}}$. As the minimum expenditure, with $x^{*}$ represented by the expenditure function $e(p, \boldsymbol{q}, U)$, the two 
individual welfare money measures associated with an improvement in $\boldsymbol{q}$ due to the archaeological strategy are returned by the following equations:

$$
W T P^{C}=e\left(p^{0}, \boldsymbol{q}^{\mathbf{1}}, U^{0}\right)-e\left(p^{0}, \boldsymbol{q}^{\mathbf{0}}, U^{0}\right)=\int_{q^{0}}^{q^{1}} \frac{\partial e\left(p, q, U^{0}\right)}{\partial q} d q
$$

And

$$
W T A^{E}=e\left(p^{0}, \boldsymbol{q}^{\mathbf{1}}, U^{1}\right)-e\left(p^{0}, \boldsymbol{q}^{\mathbf{0}}, U^{1}\right)=\int_{q^{0}}^{q^{1}} \frac{\partial e\left(p, q, U^{1}\right)}{\partial q} d q
$$

The term $\frac{\partial e\left(p, q, U^{1}\right)}{\partial q}$ in equations (1) and (2) derives from the derivative of the expenditure function with respect to $\boldsymbol{q}$. This represents the marginal value of the change in $\boldsymbol{q}$ and is theoretically equal to the income variation that is just sufficient to maintain utility at its initial level $t=0$ (in the case of the $W T P^{C}$ money measure) or the final level $t=1$ (in the case of the $W T A^{E}$ money measure,). Figure 2 geometrically portrays these two measures.

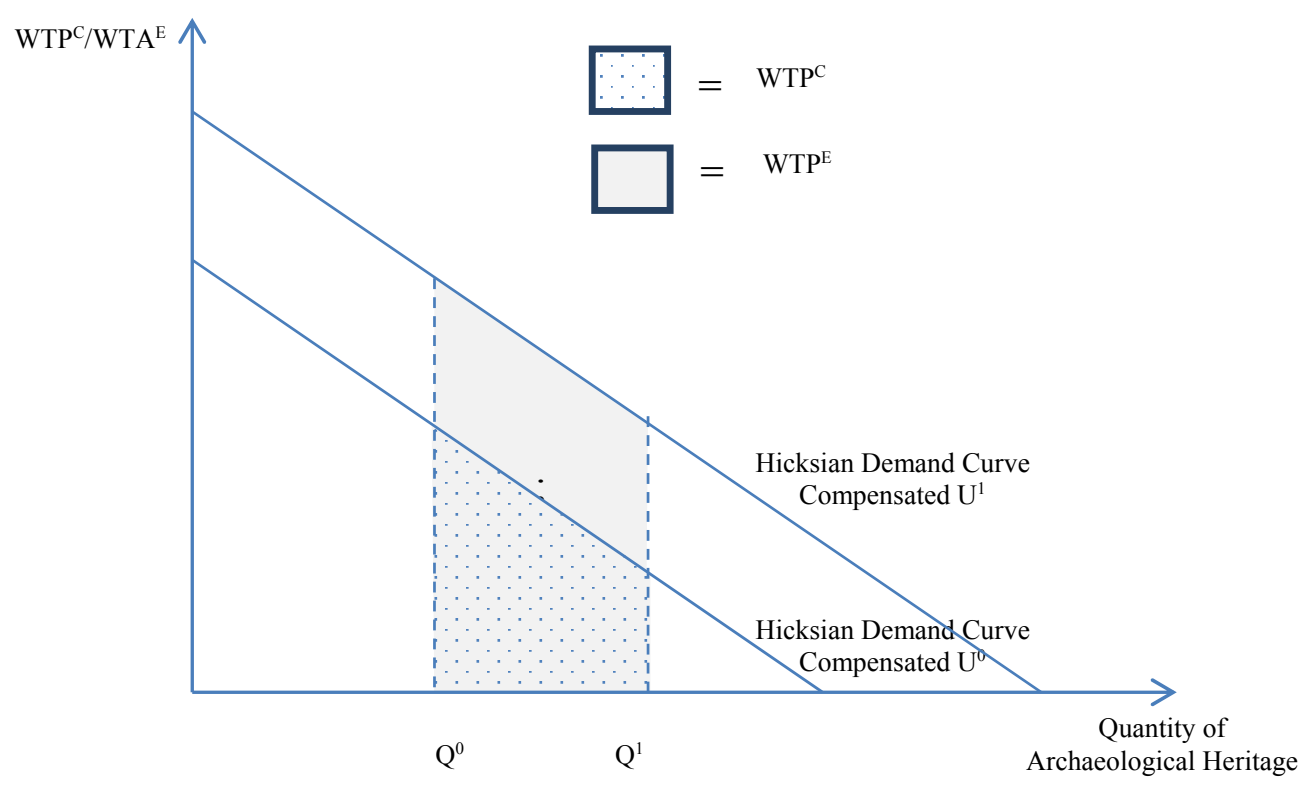

Figure 2 Graphical Representation of WTP and WTA Hicksian Welfare Money Measures

The dotted area below the Hicksian Demand curve for the amount of cultural services guaranteeing each individual consumer the utility $U^{0}$ and between the two levels of cultural services supplied just before and after the implementation of the archaeological conservation programme $-Q^{0}$ and $Q^{1}$ respectively, while $Q^{0}<Q^{1}$ - represents the maximum quantity of money each individual is willing to pay to guarantee the potential future archaeological benefits stemming from the APCP and equal to the individual's willingness to pay compensating the welfare money measure $\mathrm{WTP}^{\mathrm{C}}$. In the same figure, the shadowed area below the Hicksian Demand curve for the heritage services guaranteeing each individual consumer the utility $U^{1}$, and between the two levels of heritage services supplied before and after the implementation of the APCP $-Q^{0}$ and $Q^{1}$ respectively -, is the minimum quantity of money each individual is willing to receive in 
compensation for forgoing the potential cultural benefits that would be generated were the program to be implemented and is equal to the individual's willingness to accept equivalent (WTA ${ }^{\mathrm{E}}$ ) welfare money measure. Theoretically, the values reported by the two welfare measures differ for two reasons. The first relates with individuals holding stronger negative perceptions towards losses, which make them state higher values for compensation from the losses incurred in forgoing the program. The second reason interrelates with the $\mathrm{WTP}^{\mathrm{C}}$ measure being restricted by the individual's disposable income while the $\mathrm{WTA}^{\mathrm{E}}$ is not.

\section{Measuring the flow of benefits generated by some archaeological conservation program}

The increase in the supply of archaeological goods and services from $Q^{0}$ to $Q^{1}$ is expected to provide flows of benefits over a specific time path. The inter-temporal utilitarian approach allow us to estimate the total economic value - TEV -, generated by the archaeological conservation program over a relevant period of time $T$, by simply summing up the present value of the single-period individual welfare measures as in equation (3) [28]:

$$
T E V=\sum_{t=0}^{T} \frac{T E V^{t}}{(1+\rho)^{t}}
$$

whose continuous form is:

$$
T E V=\int_{t=0}^{T} T E V^{t} e^{-\rho t} d t
$$

Where $\rho$ is a subjective rate of time preference assumed to be positive; $T E V^{t}$ results from the estimate of the aggregated $T E V$ for the relevant population $(N)$ affected by the positive changes in the cultural flow of benefits at the moment $t$ is obtained so that $T E V^{t}=\overline{W T P}^{t}\left(\overline{W T A}^{t}\right) \times N$, with $\overline{W T P}^{t}\left(\overline{W T A}^{t}\right)$ the mean (or median) of the individual's WTP (WTA). Having defined the money measure, one may easily conclude the tackling of multidimensional benefits of archaeological remains has to go through the estimation of the TEV generated by some APCP as given by equations (3) or (4). More specifically, one has $i$ ) to assess the individual WTP/WTA for the archaeological change improved by some APCP; ii) to choose a subjective rate of time reference - $\rho$; and iii) to define a relevant period of time $T$ during which it is assumed the change will generate social and economic benefits to the population. In this paper, we are interested only in discussing how individual WTP/WTA for archaeological supply changes may be assessed through expenditure by individuals.

\section{Assessing the Individual WTP/WTA Measures for Archaeological Preservation and Conservation} Programs to Improve Local Sustainable Development

Stated-preference techniques prove the most popular valuation techniques deployed to estimate the TEV of improving environment related issues [29]. These techniques apply surveys to elicit individual WTP 
(WTA) for hypothetical changes in some environmental services along with their preferences for different contingent environmental scenarios. In this paper, we defend their full adequacy for eliciting individual WTP (WTA) for hypothetical changes in some APCP. Recourse to these techniques enables the tackling of multidimensionality benefits and therefore returning quantitative values for such programs. Through eliciting the individual's WTP/WTA, they provide a means for individuals to express their multipreferences regarding the APCP while capturing the multi-values stemming from this by means of one single amount of money.

Contingent Valuation (CV) and Choice Modelling (CM) (or Contingent Analysis) belong to this family of valuation techniques. Both are non-market valuation techniques and applied by economists every time it is necessary to assess values for actions or preferences that cannot be revealed through markets. In the case of $\mathrm{CV}$, individuals are first confronted with a hypothetical future scenario where some APCP is described alongside highlighting the expected social and economic benefits that may arise from its implementation. Individuals are then asked to express their WTP/WTA for the program and the program's benefits by contrasting them with the status quo cultural supply level and local social-economic development situation. The last step in the CV involves estimating the mean or median WTA/WTP and analysis of its sensitivity to a set of variables. In this analysis of sensitivity, a valuation function such as $W T P=\beta X+\varepsilon$ gets directly estimated and in which each stated individual WTP (WTA) incorporates a vector of $\boldsymbol{X}$ variables describing individual socio-economic characteristics (e.g. income, age, education, gender), and along with individual attitudes and perceptions towards archaeology goods, archaeological conservation programs in general, and the specific APCP at stake [30], [31], [32]. In the case of CM, individuals are asked to rank or choose their single preferred conservation scenario from a set of different hypothetical APCPs [33], [34]. Each scenario is described by a set of attributes that vary across multiple levels. By using questionnaires, individuals are exposed to an experimental design in which different combinations of scenario attributes with different levels are presented for choice in a systematic format with the main aim of identifying the key attributes to the scenario and the level that influences the individual's choice of scenario. Theoretically, CM assumes individual utility (benefit, or value) concerning some alternative APCPs, say A and B, as a function of the frequency with which he/she chooses A over B in repeated choices, as described by the Random Utility Model (RUM). The RUM model assumes individuals will always choose the scenario that maximizes his/her utility from each set of choices. The sensitivity of the individual $i$ utility $\left(U_{i j}\right)$ to the key attributes prevailing in scenario $j$ in each choice set $\left(X_{i j}\right)$ is further analyzed through the regression between individual scenario choices and the attributes of each choice set by the function $U_{i j}=\beta X_{i j}+\varepsilon_{i j}$, where $\varepsilon_{i j}$ constitutes the random error term. $\mathrm{CV}$ is by far the most popular valuation techniques applied to estimate the value of goods and services in the absence of markets (for a good picture of the theoretical and empirical history of CVM see [29]; for a synthetic although systematic overview of the theoretical and empirical history of CVM see [35] and first 
described by Bowen [36] and Ciriacy-Wantrup [37, 38]. In 1980, the method was unreservedly recognized by the U.S. federal government as an important tool for supporting judicial decisions concerning environmental issues and calculating valid estimators for welfare changes arising from environmental disasters [Clean Water Act (1972); Comprehensive Environmental Response, Compensation, and Liability Act (CERCLA) (1980)]. In 1986 and 1989, two important works [39, 32] are particularly credited for the rise in CV popularity in the USA and in European countries with the latter definitely contributing to the generalization of CV beyond environmental economics. During the 1990s, the method's reliability for monetizing environmental impacts beyond any doubt was proven once and for all. At the time, the National Oceanic and Atmospheric Administration (NOAA) asked a specifically formed expert committee chaired by the Nobel prize laureates Kenneth Arrow and Robert Solo to provide an evaluation of CV. One of the main outputs of this committee was the well-known NOAA Report [40] where CV's credibility, validity, and reliability were all clearly recognized with a number of guidelines proposed to improve the quality of subsequent empirical applications. The application of CV in quantifying the TEV of non-market services has become one of the most fiercely debated issues within environmental economic valuation literature over the last twenty years and still remains so [41] with discussion focused on the validity and reliability of CV's estimations. Detractors argue that respondents systematically provide answers inconsistent with basic assumptions of utilitarian rational choice thus non-corresponding to their real WTPs. According to this view, such an inconsistency is due to the occurrence of several types of biases with the majority arising from the way the CV gets applied to the specific object of evaluation. These include bias associated with the choice of the true Hicksian value to measure changes in individual welfare associated to the environmental change (WTP or WTA); alongside biases related with elicitation formats; information biases; anchoring biases; vehicle bias; hypothetical biases; and embedding effects [30, 31, 40, or 32 ]. However, and in spite all the criticisms, the reliability of the method for monetizing environmental impacts is actually once for all proved beyond any doubt and CV estimations are considered as valid and reliable should a number of guidelines be followed [32, 40, 42, 31, 30, or 29]. Currently, the method holds vast applications reaching far beyond the scope of environmental valuation impacts and gains broad recognition as the only means of enabling the eliciting of values for not well known multidimensional preferences likely to vary across individuals (multi-preference) and services (multi-attribute) [43]. Furthermore, CV represents the only existing valuation technique capable of generating a money measure for non-use values. CM, the other stated-preference based approach, has been drawing considerable interest as a technique for valuing the benefits stemming from the multiple cultural, social, and environmental attributes of cultural policies [44]. However, this evaluation approach has not yet been subject to the same theoretical and empirical scrutiny that $\mathrm{CV}$ has experienced. Furthermore, in $\mathrm{CM}$ questionnaires, individuals are faced with much more complex options than in their CV counterparts as respondents have to ponder trade-offs over multiple choice sets of environmental, economic, cultural, and 
social attributes. Although there have been a rising number preference valuation studies estimating the TEV of cultural goods and services over the last two decades, they still remain very few when compared with the thousands of valuation studies carried out to evaluate environmental benefits and costs. Previous surveys of valuation studies targeting cultural issues have been provided by [45, 18, and 46]. [46] refers to the existence of $72 \mathrm{CV}$ studies performed in the area of culture dealing with: the valuation of archaeological sites; historic building heritage (cathedrals, castles, and individual buildings); groups of buildings (monasteries); medieval cities; museums; theatres; arts; media broadcasts; libraries, and sports. [17] reports studies assessing economic values associated with archaeology, covering ancient monuments [47]; an ancient citadel [48]; ruins and archaeology [49, 50, 51]; maritime archaeology [52]; historic parks [53]; and heritage sites [54, 55, 56]. In a study carried out by [57], the benefits of a public program for maintaining a number of historic buildings and sites are assessed. More recent cultural valuation studies include for instance [58, 59, 60, 61, 62, 63, 64, 65, 44, 66, 67, or 68]. [58] applies a Travel Cost Method revealed preference valuation technique and a $\mathrm{CV}$ stated preference technique to estimate and compare the values of two cultural institutions. The study concludes that $\mathrm{CV}$ is the more appropriate method whenever approaching the valuation of several benefits associated with multiple cultural activities. [59] deploy contingent ranking analysis to estimate the economic benefits of tourism to sites in Jogjakarta's attributes, such as the Mount Merapi view, the Parangtritis Beach, the historical legacy of the Borodudur Temple - a UNESCO World Heritage Site -, and the living cultural heritage of Jogjakarta's Kraton. They report the attributes generate substantial economic values and support an upward review of the current admission fees. [60, 61] deploy a contingent valuation approach to design an efficient cultural policy for restoring the urban cultural heritage of the city of Valdivia in Chile. They proposed the implementation of a cultural project aimed at setting up a non-profit cultural foundation whose main function would be to undertake Valdivia's restoration program. They correspondingly applied two evaluation double-bounded contingent valuation approaches. The first yielded the value of the urban cultural heritage reported by tourists (direct-use values) with the second returning the value attributed by residents (non-use values). The first approach envisaged the ticket payment, tourists were willing to accept to secure a guided walking tour, and a double- dichotomous contingent valuation approach. In the third evaluation, the authors adopted the annual amount paid to the non-profit foundation i.e. a voluntary donation as the vehicle of payment to express the Valdivia inhabitants' WTP for the restoration and conservation of the city cultural centre. They found that the mean WTP expressed by tourists (the direct use value) was of 8.74 euros per person per visit, and the Valdivia inhabitants' mean WTP was of 6.76 euros per person per year. [62] apply a choice experiment study for a proposed restoration project aimed at preserving archaeological artefacts from Stone Age villages that are currently buried within the topsoil. The results emphasizes that even though the artefacts are not visible and might therefore not be directly used by people, the strongest preferences displayed are for ensuring patrimony preservation (which reveals intrinsic and bequest non- 
use values), rather than nurturing local ecosystems or recreational opportunities. They thus estimated the WTP for reducing the destruction of the invisible buried artefacts as 106 euros per person per year, and the WTP for ensuring permanent protection to be estimated at approximately 156 euros per person per year. [63] use a Choice Experiment to rank visitor willingness to pay for some specific attributes of the Vandolanda Fort in Hadrian's Hall. The attributes include: stopping the excavation and research conducted at the site, which are after all the key Vandolanda aim, and divert the liberated resources towards the implementation of recreational facilities such as improving visitor facilities or setting up a children's play area; introducing audio guides to boost visitor experiences; reconstructing replicas of sections of Hadrian's Hall; moving some of the many Vandolanda's unearthed artefacts to other museums; reducing or increasing the current fee paid by visitors. The study concluded that the greatest loss in value $(-27.18$ pounds) would occur if excavations and research at the side ceased, meaning visitants attribute a great value to the key aim of the site i.e excavation and research activities for cultural purposes; if the artefacts were moved to other museums, there would be a loss of utility equivalent to 18.65 pounds; with people willing to pay only 6.16 pounds to increase the amount of reconstruction, 2.94 pounds to prevent the installations of a children's play area on the site, and 2.34 pounds for the audio guide. [44, 65] conducted a $\mathrm{CV}$ approach, and a $\mathrm{CV}$ in conjunction with a $\mathrm{CA}$ approach, to assess the use benefits and non-use benefits of a preservation program for the My Son World Heritage site in Vietnam. They applied the estimated benefits for visitors (international and national) to assess optimal entrance fees able to maximize the site's revenues. They further performed a cost-benefit analysis of the preservation project to demonstrate how the CV outcomes serve to justify investments in cultural heritage preservation. The vehicle of payment applied to present the WTP of international visitors was expressed in terms of an increase in the entrance fee. National visitors were presented with a tax to finance the preservation of the site. International and national visitors were willing to pay fees of between 8.78 dollars and 2.27 dollars (the protest zero responses were included within the means estimated), respectively. Local residents were willing to pay a mean tax equal to 2.17 dollars. [66] adopt a CV approach to estimate the total economic value for Prinsep Ghat in Calcutta, India. They state that cultural heritage has to be interpreted as a complex socio-economic product instead of merely stock requiring preservation on the grounds of paternalism and thereby defending how planners should concentrate on the merit good characteristics of cultural heritage assets as potentially useful for economic, social, and ecological purposes. The Prinsep Ghat site includes a river front structure bearing an important historical and aesthetic value and very popular among Calcutta's residents. The CV approach was conducted to explore the scope for the urban regeneration of Prinsep Ghat via the development of heritage tourism on a commercial basis. An iterative bidding method served to elicit the resident WTP for the regeneration program, where alternative means of payment such as cash, bank checks, and monthly deductions on electricity bills were include to avoid any bid vehicle bias. To avoid starting bid bias, three different starting bids were used. 181 acceptable 
observations were used to estimate the local resident mean WTP per annum throughout the number of years for which individuals are willing to pay. $77 \%$ of respondents are willing to pay mainly for non-use relative motives. A median WTP per annum multiplied the number of years for which the individual remained willing to pay 6.67 dollars. [67] use a CV dichotomous-choice based approach to assess the use and intrinsic value of the Changdeok Palace site in South Korea. They applied a close-ended WTP question where respondents were asked about their WTP for a specific bid amount after being provided with detailed information about the touristic and cultural values of the cultural site: "In return for using this traditional site, would you be willing to pay more than the present admission price: YES or NO." (67, p. 319). The price bids were decided after a pre-test conducted on 50 Koreans. The mean WTP varied between 5.50 dollars and 6.00 dollars for the 442 valid observations, accordingly to the econometric model used for estimating the WTP valuation function parameters. [68], in turn, adopt a Hedonic Pricing Method to calculate the influence that cultural heritage has on the formation of housing prices, and a CV approach to estimate the recreation and the existence-value for heritage conservation. The study site features Tieler and Culemborgerwaard, a non-urban area in the south of the Netherlands, which contains many traces of Batavian settlements, Celtic fields, a Roman area, and medieval castles, church foundations and city ramparts. There is a Cultural Heritage Protection Plan for this site with a time span of ten years which entails heavy investments in archaeology, landscape, and built heritage with an estimated total cost of 36.4 million euros. 380 personal interviews were held over two months. The majority ( $85 \%)$ were willing to pay for heritage conservation and only 5.2\% were protesters. The average WTP per individual per year was 1.22 euros for recreational reasons, and 11.88 euros for bequest reasons. Summing up so far and in general terms, the findings in the literature concerning the application of stated preference valuation methods to evaluate cultural goods and services suggest that, on average, people attribute significantly positive value to the conservation, preservation and restoration of cultural capital assets, and to the cultural services they may potentially generate [69]. Visitors and locals found the destruction of or damage to cultural assets undesirable to the point of being willing to pay some amount to avoid that situation. The related mean willingness to pay values may range from very low amounts - less than one dollar per month - to higher amounts and upwards of over 150 dollars per annum. Such a dispersion of WTP values is easily explained due to different scopes and different types of CV empirical applications. In fact, they differ in accordance with the cultural change under evaluation, the hypothetical scenario used, the vehicle of payment chosen, and the frequency of payment (one-shot payments versus the payment of some fees or donations on a monthly/annual basis, for instance). One of the main characteristics of these empirical applications encapsulates the large proportion, - which may rise to $80 \%$ or even more -, of respondents stating a null WTP, although most of the zero bids are protest and thus not real bids. The WTP results seem to point to a large proportion of the population remaining unaffected by changes in cultural assets and services with positive stated values driven by only a minority of the population and typically the users 
of cultural services, the wealthier and the more educated. We would mention that there is also evidence of the importance of non-use benefits to justifying the positive WTP for cultural services.

\section{Discussion}

There are substantial reasons justifying the need to estimate the internal values of the benefits enhanced by APCP $[61,70,17,69,18]$ with the majority stemming from answers to decision-related questions including: should society spend scarce resources on APCP whose private, public and/or community benefits are uncertain, diffuse and/or hard to measure?; should private actors invest in cultural projects when the private investment returns are unpredictable or insufficient due to the merit characteristics of the cultural services?; should the answer to the later be positive, is it socially fair to have tax payers compensating private cultural investors?; in the presence of private, public, and community multi-values, who will finance the whole process and to what extent?; do cultural programs attract popular support, and to what extent do citizens feel the need to actively participate in them?; are politicians willing to accept the risk of investing in cultural programs that populations do not acknowledge or understand? In short, it seems that the merit good nature of archaeological services is a central issue to decision processes regarding how scarce resources are or are not allocated to APCPs and how archaeological institutions and services are programmed, organized, managed, monitored, and provided to citizens and stakeholders. At the same time, this must also take into consideration how, by increasing the supply of archaeological services, there are also simultaneous improvements to citizen attitudes, perceptions and cultural participation in culture, thus incentivising their consumption of cultural services and thus generating higher wellbeing levels. Therefore, the economic valuation of archaeological benefits assessed through the stated true willingness to pay for them constitutes an unquestionably important tool for archaeological planning and management, financing, and resource allocation decisions and correspondingly contributing to enhancing stakeholder and politician information levels [69]. Generating cultural information decreases the levels of uncertainty and therefore risk, two of the main limitations to archaeological conservation decisions for local sustainable development and thereby facilitating more efficient private and public decisions.

\section{Preference based economic evaluations contribute to managing culture destinations:}

This may be achieved through acknowledging local archaeological demand while improving both decisions and the management and monitoring of APCPs. Contributions from the WTP economic evaluation tool to increasing the knowledge about archaeological demand include assessing visitor multipreferences to further estimate the demand for local archaeological services and predict future demand trends; to assess how and to what extent socioeconomic characteristics such as age, income, education, degree of perception and attitudes, explain cultural demand shifts and visitor rate levels; to identify what specific social groups might get excluded from the enjoyment of archaeological services in cases adopting 
price-based archaeological management policies; to assess non-visitor potential demand for local archaeological services while investigating the factors that might influence this; to estimate price and income elasticity of demand for archaeological based cultural services; and to design pricing strategies for cultural services by identifying just who is paying, how much and when. Contributions from the economic evaluation tool to improving both the decision and management processes of the local archaeological conservation program include: i) choosing which archaeological changes (attractions, exhibitions, and improvements) should be implemented at the destination to maximize profits (revenues, taxes, or wellbeing); ii) to decide just which conservation measures should be undertaken and with what intensity and not only those concerning archaeology but also those concerning other regional cultural issues which, when mixed with the archaeological input, may play an important role in building and designing more integrated and sustainable local archaeological services; iii) additional improvements through ranking archaeological capital goods; iv) to assess the priorities related with existing and competing cultural policies at both the micro and macro levels; $v$ ) and, through evaluating the negative impacts of visitor congestion, to evaluate the impacts of previously planned mitigation measures.

\section{Preference based economic evaluations contribute to financing archaeological services:}

This may take place: i) through assessing citizen willingness to pay for the existence, conservation, preservation, improvements or the destruction of archaeological capital goods; ii) by verifying to what extent stated WTP varies with citizen socioeconomic characteristics, attitudes and perceptions; iii) through defining different pricing policies for different cultural destinations by choosing for instance among uniform-flat pricing, interpersonal price discrimination, voluntary based WTP prices, intertemporal price discrimination, or block prices; iv) through assessing the net social benefits provided by archaeological capital goods; $v$ ) through providing additional information for a multisource funding strategy involving regional and national taxes and subsidies, donations, financial funds, public/private partnerships; vi) through enabling the implementation of financial incentive systems to incentivise private stakeholder involvement and commitment towards archaeological conservation and preservation; vii) in helping public authorities design archaeological subsidy policies where WTP constitutes the pretext justifying them; viii) as a tool for setting the level of financing; ix) and, as a tool guiding decisions about the who, when, and how much.

Preference based economic evaluations contribute to helping public national and local authorities with archaeological policy decisions:

This may take place: $i)$ through allocating funds among cultural sectors and other competitive public areas, including education, health, or infrastructures, for instance; ii) through allocating cultural budgets among competitive cultural assets, cultural institutions, cities, and regions; iii) through gathering information to decide what is the most appropriate level of public, financial and non-financial, support for allocating to 
the cultural sector or to specific cultural institutions or sectors; iv) through measuring the people's satisfaction with existing cultural sector, projects, and policies, politicians gain access to a monetary measure quantifying the social-economic impact of public intervention and probing the prevailing level of popular political support; v) through gathering information useful to the public authorities and helping them redefine and refine their cultural policies; vi) through deciding whether an archaeological good is preserved or conserved and, if so, the respectively appropriate APCP.

In the specific case of the social-economic non-marketed values of some of hypogeum necropolis APCPs evaluated by means of a technique based on stated citizen preferences, such as CV or CA, the evaluations resulting may prove useful throughout out all of the aforementioned items. More specifically, the stated mean WTP for the disclosed APCP may also contribute towards helping national and local authorities taking cultural policy decisions such as:

- Deciding whether the valorisation program should be implemented; through gathering the information necessary to deciding the appropriate level of public financial, and non-financial support to be allocated to the program vis-à-vis other culturally competitive areas; assessing local inhabitant satisfaction levels over the valorisation of the entire program and the specific actions contained by means of estimating the respective WTP and thus simultaneously gathering information on the degree of local citizen agreement with the program;

- Providing additional information for a multisource funding strategy involving local and national taxes and subsidies, donations, financial funds, public/private partnerships and financial incentive systems to motivate private stakeholder involvement in the valorisation actions;

- Providing additional information on the establishing foundations necessary to designing, managing, and appraising the cultural valorisation program implementation by taking into consideration its multi-value, multi-attribute and multi- dimensional nature as a merit good, thus actively involving the stakeholders in a participatory management process;

- Assessing the social benefits provided by cultural capital goods;

- Assessing citizen willingness to pay for the existence, conservation and improvements to cultural services;

- And, analysing whether the WTP for local archaeology conservation programs varies with inhabitant socioeconomic characteristics, attitudes, and perceptions.

In addition to the WTP stated by means of the CV technique, more information about individual preferences and values may be obtained through implementing a Conjoint Analysis, hence, identifying the set of clearly defined and characterized conservation actions and stakeholder diagnosis of the progress attained by implementation.

\section{Conclusions}


The main aim of this paper involves contributing towards the discussion around the value of archaeological heritage through the lens of an economist. The path followed to achieve our main goal included three objectives. Firstly, the contribution to clarifying the concept of archaeological heritage benefits through highlighting the complexity that directly stems from their holistic characteristics. Secondly, the contribution made to assessing archaeological heritage economic and social benefits or values by demonstrating how these may be captured by means of a single variable, measured in monetary units. And, thirdly, the contribution towards explaining how such monetary variables may prove useful both to cultural heritage management for sustainable preservation and conservation improvement and to the appraisal of total private and public benefits stemming from preservation and conservation archaeological heritage projects.

We correspondingly demonstrate just how complex the definition of the entire use and non-use benefits of archaeological heritage assets may prove in accordance with applications of the economic concept of merit good. By approaching benefit analysis from the perspective of the merit good concept, we gain a powerful tool for enumerating the plethora of social and economic benefits before then classifying them across several dimensions. These dimensions then generate further returns by clarifying just which benefits can and cannot be captured by markets. We concluded this issue by recognizing that the first step in any archaeologic heritage value assessment process requires defining the plethora of benefits and classifying them across several dimensions - social, economic, environmental, institutional, political, educational, research, development - whether or not market or non-market; in order to achieve this a new definition, more broadly based on the merit good concept than that usually applied, must be considered. The second step to valuing archaeological heritage by capturing the multi-preferences in currency terms, requires choosing the most adequate methodology and technique to quantitatively evaluate the entire range of benefits and then translating them into a single monetary number. We conclude that stated preference based valuation methodologies and techniques prove the most adequate in that they monetarily capture the changes in welfare that may occur due to changes in the supply of archaeological goods and services, including changes due to non-use values. The added value these techniques brought to the archaeological heritage evaluation process stems from the way they enable the capturing of individual preferences for change in the supply of archaeological heritage and converting these into currency through means of a single popular measure. Therefore, applying preference based techniques to the issue at stake returns two advantages: firstly, they offer a means of monetizing the social and economic benefits, including those that cannot be transacted in markets, generated by the archaeological heritage; and, secondly, the money measure obtained through the application of such techniques constitutes a guarantee that this (at least approximately) reflects the perceptions and attitudes of citizens towards the respective ACPP and attaining both statistical significance and theoretical validity. We then completed a literature survey to gain deeper insights into the empirical cultural valuation evidence based on preference stated techniques. We conclude 
that the contingent valuation approach proves the most common although conjoint analysis is currently increasingly being deployed when the objective at stake includes choosing and evaluating different archaeological preservation and conservation scenarios with different characteristics. The higher the frequency of usage of the contingent valuation technique also arises from its capacity to simultaneously capture use and non-use values. Finally, in the last section, we discussed some insights into how this type of archaeological heritage evaluation may serve the objective of contributing towards supplying additional quantified information on the putative ACPP generated social and economic impacts, thus clearly contributing to lowering the uncertainty, which remains one of the greatest restrictions on both public cultural heritage policy choices and private cultural heritage investments.

We conclude by emphasizing that archaeological heritage is a particularly complex capital asset that renders its respective decision-making processes, management, and monitoring a holistic scenario calling for inter-personal, inter-institutional, and inter-science participation.

\section{Acknowledgments}

This paper is one output of the Project «Funerary practices in the Alentejo's Recent Prehistory and the socio-economic proceeds of heritage rescue projects» and funded through the Portuguese national funding agency for science, research and technology (FCT) under the projects PTDC/HIS-ARQ/114077/2009 and UID/SOC/04521/2013.

\section{References}

[1] Jorge, P. C. 2012, Práticas Funerárias da Pré-História Recente no Baixo Alentejo e Retorno Socioeconómico de Programas de Salvamento Patrimonial. Modelo Genérico de Valorização e Modelo Específico para Brinches e Sobreira de Cima, Active Património Vivo, Lisbon.

[2] UNESCO, (1972), Convention Concerning the Protection of the World Cultural and Natural Heritage. Paris, November 16th. http://whc.unesco.org/archive/convention-en.pdf (Last access: 29th November 2015).

[3] ICOMOS, International Cultural Tourism Charter, (2002), Principles and Guidelines for Managing Tourism at Places of Cultural and Heritage Significance, ICOMOS International Cultural Committee. http://www.heritagemalta.org/erdf032/documents/06 ICOMOS\%20International\%20Cultural\%20Tourism\%20Charter.pdf (Last access: 29th November 2015).

[4] ICCROM, (2005), Definition of Cultural Heritage. Selected by J. Jokilehto (Originally for ICCROM, 1990) Revised for CIF: 15 January 2005. ICCROM Working Group 'Heritage and Society' http://cif.icomos.org/pdf docs/Documents\%20on\%20line/Heritage\%20definitions.pdf (Last access: 29th November 2015).

[5] Mazzanti, M., (2002), Cultural Heritage as Multi-Dimensional, multi-value and multi-attribute economic good: Toward a New Framework for Economic Analysis and Valuation, Journal of Socio-Economics, 31, p. 529-558.

[6] Musgrave, R. (1959), The Theory of Public Finance, McGraw-Hill, New York.

[7] -- (1957), A Multiple Theory of Budget Determination, FinanzArchiv, XVII(3), 333-343.

[8] Throsby, D. and Withers, A., (1985), What Price Culture?,Journal of Cultural Economics, 9(2), p. 1-34.

[9] Cwi, D., (1980), Public Support for the Arts Three Arguments Examined, Journal of Cultural Economics, 4(2), p. 39-62.

[10] Netzer, D., (1978), The Subsidised Muse, Cambridge University Press, Cambridge.

[11] Musgrave, R. A., (2008), Merit Good, The New Palgrave Dictionary, Edited by Steven N. Durlauf and Lawrence E. Blume.

[12] Lipe, W., (1984), Value and Meaning in Cultural Resources, in Clleere, H., (Ed), (1984), Approaches to the Archaeological Heritage, Cambridge University Press, New York.

[13] Frey, B., (1997), The Evaluation of Cultural Heritage: Some Critical Issues. In Economic Perspectives on Cultural Heritage, Huter, M. and Rizzo, I., (Eds), (1997), Economic Perspectives on Cultural Heritage, MacMillan, London.

[14] English Heritage, (1997), Sustaining the Historic Environment: New Perspectives on the Future, English Heritage Discussion Document, English Heritage, London.

[15] Australia ICOMOS, (2000), The Burra Charter Australia. The Australia ICOMOS Charter for Places of Cultural Significance 2013, Australia ICOMOS, Inc. Faculty of Arts, Deaking University: Australia . http://australia.icomos.org/wp-content/uploads/The-Burra-Charter-2013-Adopted-31.10.2013.pdf (Last access: 13th Novembre 2015).

[16] Mason, R., (2002), Assessing Values in Conservation Planning: Methodological Issues and Choices, in Getty Conservation Issue (2002), Assessing the

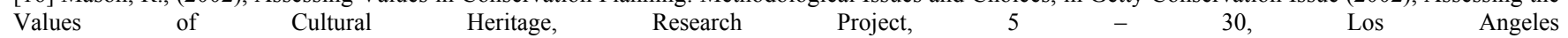
(http://www.getty.edu/conservation/publications_resources/pdf_publications/pdf/assessing.pdf; (Last access: 16 ${ }^{\text {th }}$ November 2015).

[17] Provins, A., Pearce, D., Ozdemiroglu, E., Mourato, S., Morse-Jones, S., (2008), Valuation of the Historic Environment: the Scope for Using Economic Valuation Evidence in the Appraisal of Heritage-Related Projects, Progress in Planning, 69, p. 131-175.

[18] Navrud, S. and Ready, R., (2002), Why Value Cultural Value?, in Navrud, S. and Ready, R. (eds), (2002), Valuing Culture Heritage: Applying Environmental Valuation Techniques to Historic Buildings, Monuments, and Artefacts, p. 3 - 9, Edward Elgar, Cheltenham, UK. 
[19] Frey, B. (2005), What Values Should Count in the Arts? The Tension Between Economic Effects and Cultural Value, WP n ${ }^{\circ} 253$, Institute for Empirical Research in Economics, University of Zurich, Zurich.

[20] Esteves, A. M. and Barclay, M-A., (2011), Enhancing the Benefits of Local Content: Integrating Social and Economic Impact Assessment Into Procurement Strategies, Impact Assessment and Project Appraisal, 29(3), p. 205-215.

[21] Hicks, J.R., (1939), The Foundations of Welfare Economics, Economic Journal, 49(196), p. 696-712.

[22] Kaldor, N., (1939), Welfare Propositions of Economics and Interpersonal Comparisons of Utility, Economic Journal, Volume no 49 , p. 549-552.

[23] Mäler, K.G., (1974), Environmental Economics: a Theoretical Inquiry, Johns Hopkins University Press, Baltimore.

[24] Mäler, K.G., (1971), A Method of Estimating Social Benefits from Pollution Control, Swedish Journal of Economics, Volume 73, $121-133$.

[25] Johansson, P-O, (1987), The Economic Theory and Measurement of Environmental Benefits, Cambridge University Press, Cambridge, UK.

[26] Kopp R.J. et al, (1997), Constructing Measures of Economic Value, in Kopp R.J. et al (eds), Determining the Value of Non-Marketed Goods, Kluwer Academic Publications, USA, p.101-126.

[27] Jakobsson K.M. et al, (1996), Contingent Valuation and Endangered Species. Methodological Issues and Applications, Elgar, Cheltenham.

[28] Mendes, I.(2004), Valuing Acosystems. A Approach, Methodological Ang Ang A 11/2004/DE/CIRIUSWP, ISEG Lisbon School of Economics and Management, Lisbon University. [29] Carson, R.T. and Hanemann, M. (2005), Contingent Valuation, in Mäler, K.-G., et al (eds.) (2005), Handbook of Environmental Economics. Valuing Environmental Changes, Volume 2, Chapter 17 ${ }^{\text {th }}$, North-Holland, Elsevier, Amsterdam.

[30] Alberini, A. and Kahn, J. R., eds., (2006), Handbook on Contingent Valuation, Edward Elgar Publishing, Cheltenham.

[31] Freeman AM III, (2003). The Measurement of Environmental and Resource Values: Theory and Methods, Resources for the Future, Washington DC.

[32] Mitchell R.C. et al, (1989), Using Surveys to Value Public Goods: the Contingent Valuation Method. Resources for the Future, Washington DC.

[33] [Louviere, J., Hensher, D., and Swait, J., (2000), Stated-Choice Models - Analysis and Application, Cambridge University Press, Cambridge, UK.

[34] Bennett, J. and Blamey, R., (2001), The Choice Modelling Approach to Environmental Valuation, Edward Elgar, Cheltenham, Northampton, UK.

[35] Mendes, I., Sardinha, I. D., and Milheiras, S. (2013), Methodological Issues for Estimating the Total Value of the Rehabilitation of Mining Fields: the Case of S. Domingo's Mine, International Journal of Latest Trends in Finance and Economic Sciences, Vol-3 (4), December, p. $593-610$.

[36] Bowen, H.R., (1943), The interpretation of voting in the allocation of economic resources, Quarterly Journal of Economics, Volume 58, p. 27-48.

[37] Ciriacy-Wantrup, S.V., (1952), Resource Conservation: Economics and Policies, University of California Press, Berkeley.

[38] Ciriacy-Wantrup, S.V., (1947), Capital returns from soil-conservation practices, Journal of Farm Economics, 29, p. 1181-1196.

[39] Cummings, D. S., et al, (1986), Valuing Environmental Goods: an Assessment of the Contingent Valuation Method, Rowman\&Allanheld, Totowa NJ.

[40] Arrow K. et al., (1993), Report of the NOAA Panel on Contingent Valuation, Federal Regulation, Volume ${ }^{\circ} 58,4601$ et seg..

[41] Lo, A.Y. and Spash, C. L. (2012), Deliberative Monetary Valuation: In Search of a Democratic and Value Plural Approach to Environmental Policy, Journal of Economic Surveys, DOI: 10.1111/j.1467-6419.2011.00718.

[42] Portney P.R., (1994), The Contingent Valuation Debate: Why Economists Should Care, Journal of Economic Perspectives, 8 (4), p. 3-17.

[43] Borghi, J. et al., (2007), Using Focus Groups to Develop Contingent Valuation Scenarios - A Case Study of Women's Groups in Rural Nepal, Social Science \& Medicine, 64, p. 531-542.

[44] Tuan, T. H., and Navrud, S., (2007), Valuing Cultural Heritage in Developing Countries: Comparing and Pooling Contingent Valuation and Choice Modelling Estimates, Environmental Resource Economics, 38, p. 51-69.

[45] Pearce, D., and Mourato, S., (1998), The Economics of Cultural Heritage, World Bank Support to Cultural Heritage Preservation in the MNA Region, Center for Social and Economic Research on the Global Environment (CSERGE), University College London, London.

[46] Noonan, D. S., (2003), Contingent Valuation and Cultural Resources: A Meta-Analytic Review of the Literature, Journal of Cultural Economics, 27 (3 4), p. $159-176$.

[47] Maddison, D., and Mourato, S., (2002), Valuing Different Road Options for Stonehenge. In Navrud, S., and Ready, R. (eds), (2002), Valuing Culture Heritage: Applying Environmental Valuation Techniques to Historic Buildings, Monuments, and Artefacts, Edward Elgar, Cheltenham, UK.

[48] Mourato, S., Ozdemiroglu, E., Hett, T., and Atkinson, G, (2004), Pricing Cultural Heritage: A New Approach to Managing Ancient Resources, World Economics, 5 (3), $95-113$.

[49] Boxall, P. C., Englin, J., and Adamowicz, W. L., (2003), Valuing Aboriginal Artifacts: A Combined Revealed - Stated Preference Approach, Journal of Environmental Economics and Management, 45 (2), p. 213 - 230.

[50] Poor, P. J., and Smith, J. M., (2004), Travel Cost of a Cultural Heritage Site: the Case of Historic St Mary's City of Maryland, Journal of Cultural Economics, 28 (3), p. $217-229$.

[51 ] Riganti, P. and Willis, K.G., (2002), Component and temporal value reliability in cultural goods: the case of Roman Imperial remains near Naples, in Navrud, S. and Ready, P., eds., (2002), Valuing cultural heritage: applying environmental valuation techniques to historic buildings, monuments, and artifacts, Edward Elgar, Cheltenham, p. 142-158.

[52] Whitehead, J. C., and Finney, S. S., (2003), Willingness to Pay for Submerged Maritime Cultural Resources, Journal of Cultural Economics, 27 (3-4), p. $231-240$

[53] Willis, K. G., (2002), Iterative Bid Design in Contingent Valuation and the Estimation of the Revenue Maximizing Price for Cultural Good, Journal of Cultural Economics, 26(4), p. $307-324$.

[54] Alberini, A., and Longo, A. (2006), Combining the travel cost and contingent behavior methods to value cultural heritage sites: Evidence from Armenia, Journal of Cultural Economics, 30(4), p. 287-304.

[55] Alberini, A., Rosato, P., Longo, A., and Zanatta, V., (2005), Information and Willingness to Pay in a Contingent Valuation Study: The Value of S. Erasmo in the Lagoon of Venice, Journal of Environmental Planning and Management, 48(2), p. 155-175.

[56] Rolfe, J., and Windle, J., (2003), Valuing the Protection of Aboriginal Cultural Heritage Sites, The Economic Record, 79 , p. 85 - 95.

[57] Santagata, W., and Signorello, G., (2002), Individual Preferences and Allocation Mechanisms for a Cultural Public Good: Napoli Musei Aperti, in Navrud,

D., and Ready, R. (eds.), (2002), Valuing Cultural Heritage: Applying Environmental Valuation Techniques to Historic Buildings, Monuments and Artefacts, Edward Elgar, Cheltenham, UK, p. $238-253$.

[58] Ambrecht, J., (2014), Use Value of Cultural Experiences: A Comparison of Contingent Valuation and Travel Cost, Tourism Management, 42, p. 141-148. [59] Othman, J. and Rahajeng, A., (2013), Economic Valuation of Jogjakarta's Tourism Attributes: A Contingent Ranking Analysis, Tourism Economic, February.

[60] Báez, A., Bedate, A. M., Herreo, L. C., and Sanz, J. A., (2012), Inhabitant's Willingness to Pay for Cultural Heritage: A Case Study in Valdivia, Chile, Using Contingent Valuation, Journal of Applied Economics, 15 (2), p. 235 - 258.

[61] Báez, A. and Herrero, L. C. (2012), Using Contingent Valuation and Cost-Benefit Analysis to Design a Policy for Restoring Cultural Heritage, Journal of Cultural Heritage, 13 (3), p. $235-245$.

[62] Lunhede, T., Bille, T., and Hasler, B., (2012), Exploring Preferences and Non-Use Values for Hidden Archaeological Artefacts: a case from Denmark, International Journal of Cultural Policy, DOI: 10.1080/10286632.3011.652624.

[63] Kinghorn, N., and Willis, K., (2008), Valuing the Components of an Archaeological Site: An Application of Choice Experiment to Vindolanda, Hadrian's Hall, Journal of Cultural Heritage, 9, p. $117-124$.

[64] Willis, K. G. (2002), Iterative Bid Design in Contingent Valuation and the Estimation of the Revenue Maximizing Price for Cultural Good, Journal of Cultural Economics, 26(4), p. $307-324$.

[65] Tuan, T- H., and Navrud, S., (2008), Capturing the Benefits of Preserving Cultural Heritage, Journal of Cultural Heritage, 9 (3), p. 326 - 337.

[66] Dutta, M., Banerjee, S., and Husain, Z., (2007), Untapped Demand for Heritage: A Contingent Valuation Study of Prinsep Ghat, Calcuta, Tourism Management, 28, p. $83-95$. 
[67] Kim, S. S., Wong, K. K. F., and Cho, M., (2007), Assessing the Economic Value of a World Heritage site and Willingness - to- pay Determinants: A Case Study of ChangdeoK Palace, Tourism Management, 28 (1), p. 317 - 322.

[68] Ruijgrok, E. C. M., (2006), The Three Economic Values of Cultural Heritage: a Case Study in the Netherlands, Journal of Cultural Heritage, 7, p. 206 213.

[69] Mourato, S. and Mazzanti, M., (2002), Economic Valuation of Cultural Heritage: Evidence and Prospects, in Getty Conservation Issue, (2002), Assessing the Values of Cultural Heritage, Research Project, 5 Angeles (http://www.getty.edu/conservation/publications_resources/pdf_publications/pdf/assessing.pdf; (Last access: 11 $1^{\text {th }}$ November, 2015).

[70] Vandermeulen, V., Verspecht, A., Vermeire, B., Van Huylenbroeck, G., Gellynck, X., (2011), The Use of Economic Valuation to Create Public Support for Green Infrastructure Investments in Urban Areas, Landscape and Urban Planning, 103, p. 198 - 206. 